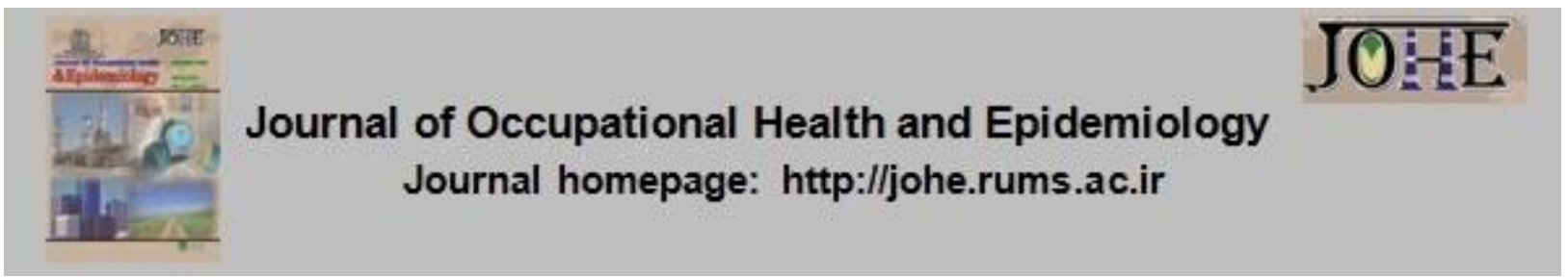

\title{
Hospital information system and working process of both managers and network users in Ali ibn Abi Talib Hospital of Rafsanjan, Iran
}

\author{
Masoud Iranpour ${ }^{1}$, Adel Soleimani Nejad ${ }^{2}$, Fariborz Doroudi ${ }^{3}$, Zahra Saeedifard ${ }^{4}$, \\ Hassan Alinezhad ${ }^{5}$, Mohammad Ziaadini, \\ 1- MSc in Information Science, Management Information System, Rafsanjan Branch, Islamic Azad University, \\ Rafsanjan, Iran. \\ 2- Assistant Prof., in Information Science, Department of Information Science, Shahid Bahonar University, Kerman, \\ Iran. \\ 3- Faculty Member of Iranian Research Institute for Information Science and Technology, Kerman, Iran. \\ 4- MSc in Network Engineering, Rafsanjan University of Medical Sciences, Rafsanjan, Iran. \\ 5- PhD Student in Management, Department of Management, Rafsanjan Branch, Islamic Azad University, Rafsanjan, \\ Iran. \\ 6- Assistant Prof., Department of Management, Rafsanjan Branch, Islamic Azad Uneversity Rafsanjan, Iran.
}

\section{Article Info}

* Corresponding authors:

Mohammad Ziaadini,

E-mail:

mziaaddini@yahoo.com

\section{Article history}

Received: Dec, 2016

Accepted: Dec, 2017

Print ISSN: 2251-8096

Online ISSN: 2252-0902

Peer review under responsibility of Journal of Occupational Health and Epidemiology

\section{Abstract}

Background: The present study was conducted with the aim to determine the effect of hospital information system (HIS) on the performance and working process of managers and network users of Ali ibn Abi Tileb Hospital of Rafsanjan, Iran.

Materials and Methods: This research was conducted on employees of Ali ibn Abi Talib Hospital in Rafsanjan ( $n=650$ individuals). The study sample volume was determined using the Cochran formula ( $n=250$ subjects). In this research, stratified random sampling method was used in proportion to the size of the sample. In the present research, the data collection tool was a valid questionnaire, with a Cronbach's alpha value of greater than 0.7 . The collected data were analyzed using SPSS software.

Results: Based on the results obtained for the discipline component, the $P$ value was less than 0.05 . The mean score in the one-sample test was larger than the mean average limit, and the HIS had a positive effect on discipline in the performance of managers and users $(P<0.05)$.

Conclusions: Due to the importance of the HIS knowledge, one can increase the performance of users and also facilitate the admission and discharge affairs of patients, and hence, achieve the desired state, which is the patient's satisfaction.

Keywords: Hospital Information System, Managers, Employees, Performance

\section{Introduction}

With the increasing development of hospitals, their mission of meeting the expectations of the patients has become more susceptible and more important. Hospitals are responsible for continuously monitoring patients' satisfaction and must take the necessary measures in this regard as soon as possible. Neglecting the factors causing dissatisfaction among patients can endanger the goals of the hospital in the long run (1). Therefore, today, information is one of the most important sources of power in the world. Information is the basis of planning and decision making. Making

(C) The Author(s) 2018. Published by Rafsanjan University of Medical Sciences Press.

All rights reserved. For permissions, please e-mail: johe.rums@gmail.com, johe@rums.ac.ir 
decisions in present-day disturbed environments, without continuous access to relevant information, causes confusion in practice. The designing and establishing of systems and the application of information technology (IT) in general and in management information systems (MIS), in particular, is an attempt to respond to this need in the information age. The foundation of all management activities is comprehensive, relevant, and timely information (2). In the designing of information systems, it is necessary to consider different levels of managers, as this affects both the information resources and the way of its presentation (3). Hospital information systems (HISs) are patientcentered, integrated, and coherent; in addition, they have many benefits in the fields of health and treatment. These systems can even communicate with external databases in order to eliminate barriers and communicate effectively. The application of hospital information technology guidelines is associated with many challenges. Prior to applying these guidelines, it is necessary to be accurately aware of the complexities of the hospital's internal environment, including the high level of specialties, hospital's role and mission sensitivity, hospital's complex intersectorial and intra-sectorial connection, and etc. In addition to technical issues and technical standards, semantic coordination and content communication among different internal and external parts of such a system is also an important and extensive discussion (4). Moreover, the implementation of the HIS can be discussed from the two important technological and MIS perspectives. First, HIS is a kind of change in the technology of providing hospital services. The second perspective addresses the role of the hospital management information system in providing information to the management in order to perform more effective hospital activities. If accurate and comprehensive information is provided to managers in a timely manner, the risk of making false decisions will be minimized. Today, computers are used to provide such information in various fields, and MISs have taken measures to provide information in a wide range of areas required by management, especially in large and advanced organizations (5).

Managers, at all organizational levels, have realized that the computer information system can provide the necessary information for effective operations. Today, MIS is gaining increasing importance in planning, decision making, and optimum control. The degree of success of a control system depends on how quickly managers can acquire accurate information regarding what is happening according to the plan and what is being diverted from its path (6).

In the following, the necessity of the HIS has been emphasized based on its effective implementation of and positive impact on health care services, which are of great importance. This includes evaluating, measuring, and monitoring all aspects of planning, progress, implementation and its related activities, and the results leading to decision making in that particular environment. The systematic evaluation of HIS supports the clinical activities of health care staff, so that through adapting the software to the needs of staff and network users, it can continually improve their performance, prevent medical errors, and reduce stressful responses and related costs (7).

The role of the HIS in improving the performance of hospital management and its treatment staff is also irrefutable; in addition, most of the management scientists and scholars have recommended it without uncertainty. Furthermore, managers also believe that the application of HIS is inevitable in order to make changes in hospitals (8).

The goal of the HIS is to exploit computers and communication equipment to collect, 
store, process, extract, and coordinate care and management information. In other words, the data of this system are stored in a way to be available to users at the time and place required. An important feature of this system is that its operation is based on the standards. Moreover, it does not only create compulsory changes in manual systems, but also adapts itself to them, operates on the basis of medical events, and is not dependent on the patient's movement cycle.

The compatibility of HIS with the work plans of health staff will make it easier for them to carry out their specialized occupations. Moreover, in the case of accurate designing of HISs, the effectiveness and efficiency of caregivers and patient satisfaction will increase and health care costs will decrease. In other words, the lack of compatibility of the HIS duties with existing processes can affect the costs and quality of health care. Therefore, in the present study, regarding the goals of these systems, the effect of these systems on the performance of work processes was investigated from the viewpoint of managers and network users in Ali ibn Abi Talib Hospital of Rafsanjan, Iran, as recognition of the requirements, will facilitate the resolving of possible problems.

\section{Material and Methods}

This descriptive study was conducted using path analysis method. The statistical population of the study consisted of all managers and network users related to the HIS of Ali ibn Abi Talib Hospital of Rafsanjan ( $\mathrm{n}=650$ individuals). A sample size of 250 individuals was determined using the Jersey and Morgan table and stratified random sampling method. The data collection tool was a questionnaire consisting of 20 questions and including the components of creating discipline, reducing the volume of work, speeding up the work, and satisfaction rate. The items were scored based on a five-point scale ranging from 1-5 (strongly disagree, disagree, relatively agree, agree, and totally agree, respectively). After describing how to complete the questionnaire, it was distributed among the HIS managers and users. The questionnaires were collected and analyzed using the ratio test in SPSS software (SPSS Inc., Chicago, IL, USA).

\section{Results}

According to the data analysis, of the subjects under study, $112(44.8 \%)$ and 138 $(55.2 \%)$ were men and women, and 73 (29.2\%) and 177 (70.8\%) were married and single, respectively. In addition, among the subjects, 74 (29.6\%), 91 (36.4\%), and 85 (34\%) had a bachelor's degree, a master's degree, and a $\mathrm{PhD}$, respectively. The ratio test was used to examine the effect of the HIS on the processes of managers and users.

Table 1: Ratio test results regarding the effect of HIS on the performance of managers and users

\begin{tabular}{ccccccc}
\hline & $\begin{array}{c}\text { Number of managers } \\
\text { and users }\end{array}$ & Total & $\begin{array}{c}\text { Test } \\
\text { statistic }\end{array}$ & $\begin{array}{c}\text { Sample } \\
\text { ratio }\end{array}$ & $\mathbf{P}^{*}$ \\
\hline $\mathbf{1}$ & Work speed & 155 & 250 & 4.11 & 0.62 & $<0.001$ \\
\hline $\mathbf{2}$ & Discipline & 158 & 250 & 4.46 & 0.63 & $<0.001$ \\
\hline $\mathbf{3}$ & Satisfaction & 162 & 250 & 5.05 & 0.64 & $<0.001$ \\
\hline $\mathbf{4}$ & Reduced workload & 142 & 250 & 2.35 & 0.56 & $<0.002$ \\
\hline${ }^{*}$ P-Value $<0.05$ & & & & &
\end{tabular}

As shown in table 1, more than half of the respondents believed that the HIS affects the performance and work processes of managers and users (speed of work, discipline, satisfaction, and reduced workload); the Friedman test was used for 
this purpose. As can be seen in table 2, the HIS has the greatest effect on satisfaction.
The other priorities are respectively given in the table.

Table 2: Prioritization of the effect of HIS on the performance of managers and users

\begin{tabular}{ccc}
\hline Rank & Feature & Average rating \\
\hline 1 & Satisfaction & 3.24 \\
\hline 2 & Discipline & 2.73 \\
\hline 3 & Work speed & 2.48 \\
\hline 4 & Workload & 1.55 \\
\hline
\end{tabular}

\section{Discussion}

The results of this study showed that the HIS affected the performance of managers and users of Ali ibn Abi Talib Hospital of Rafsanjan. This finding is in agreement with the findings of the studies by Asadi et al. (1), Amiri et al. (5), Kahouyi et al. (6), and Kao and Chang (7). Asadi et al. studied the role of the HIS in improving the performance of Iranian hospitals (1). The purpose of the researcher in this study was to review the essential points of the HIS and the capabilities of this system in improving the performance of hospitals (2). The findings of the comparison of processes between manual and computerized systems indicated that using HIS significantly reduced the processes effective on the length of hospitalization of patients and improved the performance of hospitals (1). Amiri et al., conducted a study entitled "Selfassessment of network managers and users on the impact of the hospital information system (HIS) on the performance and work processes of Imam Hossein Hospital of Shahroud, Iran" (5). Their findings showed that in order to improve the attitude of all users, especially managers (due to the low scores of attitude), holding training workshops on the application of new information technologies in effective management and presentation of an overview of network operation with approaches of cost-efficiency, cost-benefit, and cost-effectiveness analyses can help improve the current status (2). Kao and Chang evaluated the rate of acceptance of HIS by physicians and nurses (7). They found that $60 \%$ of nurses were satisfied with the system's benefits and $44 \%$ of them with its convenient use (7). Rahnomoud and Ershadi in a research on the application of MIS, stated that the full and comprehensive application of information systems, especially health information systems, is possible when all components and software of these systems are predicted and implemented (8).

Every research is accompanied by some limitations on the path to its realization which cause problems for conducting the research and make the generalization of the results difficult. The present study was not an exception to this rule, and the lack of response to some questions by individuals in several cases led to the completion of alternative questionnaires by others.

Regarding the subject of the research, after the completion of the study, some issues are presented as proposals for future studies that are expected to be of interest to researchers interested in the subject of the present research. It is recommended that in future studies, the indicators related to HIS be considered with new items and items different from those of this research. In addition, the subject under study can be investigated in other similar health care centers.

\section{Conclusion}

HIS has many capabilities and increased values with the ability to revolutionize hospital services. Improving the quality of health care, creating a scientific management in the hospital administration, 
improving the economy of treatment, developing research in medical sciences, reforming policymakers in health care, and developing medical education are the benefits of this system.

\section{Acknowledgements}

Undoubtedly, the present research could not be carried out without the cooperation of the intensive staff of Ali ibn Abi Talib Hospital; therefore, their collaboration is sincerely appreciated.

\section{Conflict of interest: None declared.}

\section{References}

1- Asadi F, Moghaddasi H, Hosseini A, Dehghani M. Situation Analysis of outpatient information management systems in hospitals affiliated with universities of medical sciences, Tehran, Iran. Health Information Management 2012; 9(3):432-9.

2- Amiri M, sadeghi E, Khosravi A, Chaman R. Self-assessment of the managers and network operators about the effect of hospital information system on the performance and processes of Imam Hussoin hospital in Shahroud. Health Information Management 2011; 8(4):490-9.

3- Hashem Zahi A, Irannejad Parizi M, Tabibi SG, Hashem Zahi M. the relationship of information systems and the effectiveness of performance measurement systems in educational hospitals inTehran. [Internet]. 2011 [cited 2011 Oct 19]. Available from: http://marketingarticles.ir/ArtBank/Asarbakhs hiNezamSanjesh.pdf

4- Blobel B. Ontology driven health information systems architectures enable pHealth for empowered patients. Int J Med Inform 2011; 80(2):e17-e25.

5- Dargahi H , Ghazi Saeedi M, Safdari R, Hamedan M. A Survey of clinical information system process in general hospitals of Tehran University of Medical Sciences. Payavard Salamat 2010; 4(1-2):31-43.

6- Kahouei M, Eskrootchi R, Ebadi Fard AF, Abolhassani $H$. Triage Staff Expectations data model: Hospital Emergency Information System. Health Information Management 2013; 10(3):1-12

7- Kuo NW, Chung YY. The application of healthcare information system for comprehensive geriatric assessment. MIS Review 2012; 17(2):87-98.

8- Arshadi J. Study of effictivnes management infirmation system in development and engeneering deputy of $\mathrm{co} \mathrm{MCl}$ of east azarbaeijan province. [MSc thesis]. Tabriz: Azad University of Tabriz; 2011.

9- Shafiei Nikabadi M, Naghipour N. A model for assessing hospital information systems. Journal of Health Administration 2015; 18(60):50-66.

10- Raeisi A, Dadashi Z. The study of educational needs managers in hospitals affiliated with Isfahan University of Medical Scirnces based on health information systems in 2006. Journal of Health Information Management 2006; 3(1):19-24 